\title{
Transparent reversible prosthesis, a new way to complete the conservation-restoration of a Black Ding bowl with application of 3D technologies
}

Shengyu Liu ${ }^{1 \dagger}$, Yuanwei Tu ${ }^{1 \dagger}$, Xin Wang ${ }^{1}$, Bo Qin² ${ }^{2}$ Zhenda Xie ${ }^{3}$, Yeliang Zhang ${ }^{1}$, Hai Zhang ${ }^{1 *}$ and Dongbo Hu ${ }^{{ }^{*}}$

\begin{abstract}
In recent years, 3D technology has been widely used in various aspects of the entire workflow of conservation-restoration. However, in the majority of cases, researchers have mainly relied on 3D technologies to assist the conventional conservation-restoration process, and its advantages have not truly been exploited. In this paper, we applied a combination of digital acquisition, virtual anastylosis, virtual reconstruction, and 3D printing of a transparent reversible prosthesis with slots for the restoration of a gold foil decorated Black Ding bowl collected by the Chifeng Museum of the Inner Mongolia Autonomous Region. While completing the physical/aesthetic restoration of the artifact, the conservation-restoration principles of the integrity and authenticity of cultural heritage, minimal intervention and reversibility were followed to the utmost extent. At the same time, we also conducted preliminary performance tests on the 3D printing material of the prosthesis, and the results showed that the material has excellent mechanical properties and stain resistance, contributing to the long-term, stable preservation of the artifact. This work presents an innovative solution applicable to other pieces of cultural heritage and has high significance for promotion.
\end{abstract}

Keywords: 3D technology, Virtual conservation, 3D virtual model, 3D print, Transparent reversible prosthesis, Gold foil decorated Black Ding artifact

\section{Introduction}

Since its appearance in the 1980s, 3D technology has experienced strong and rapid growth and is widely used in industrial design, architecture, engineering construction, aerospace, surgery, and many other fields [1-3]. Among them, the comprehensiveness of digital acquisition, the innovative potential of digital modeling, and the efficiency of digital manufacturing also provide new ideas and vitality for cultural heritage $(\mathrm{CH})$ [4]. Documentary records about the important applications of $3 \mathrm{D}$

\footnotetext{
*Correspondence: haizhang@pku.edu.cn; hudongbo@pku.edu.cn

†'Shengyu Liu, and Yuanwei Tu contributed equally to this work and are considered co-first authors

${ }^{1}$ The International Center for Chinese Heritage and Archaeology, School of Archaeology and Museology, Peking University, Beijing 100871, China Full list of author information is available at the end of the article
}

technologies in $\mathrm{CH}$ began to appear in the mid-1990s [5-7]. Subsequently, concepts such as virtual heritage [8], virtual archaeology [9], and virtual conservation [10] were gradually introduced.

The documentation requirements of cultural relics (archaeological sites [11-13], buildings [14], murals [15, 16], sculptures [6, 7], etc.) should be the initial application of 3D technologies in the field of cultural heritage to address potential threats such as natural disasters [15], damage by human activity [17], and other reasons. The virtual heritage model obtained from digital acquisition and digital modeling can make heritage information survive in the long term, providing the possibility for emergency preservation and even reproduction of cultural relics after damage [17-19]. In addition, virtual heritage has become a continuation of scientific research activities
Springer Open

(c) The Author(s) 2022. Open Access This article is licensed under a Creative Commons Attribution 4.0 International License, which permits use, sharing, adaptation, distribution and reproduction in any medium or format, as long as you give appropriate credit to the original author(s) and the source, provide a link to the Creative Commons licence, and indicate if changes were made. The images or other third party material in this article are included in the article's Creative Commons licence, unless indicated otherwise in a credit line to the material. If material is not included in the article's Creative Commons licence and your intended use is not permitted by statutory regulation or exceeds the permitted use, you will need to obtain permission directly from the copyright holder. To view a copy of this licence, visit http://creativecommons.org/licenses/by/4.0/. The Creative Commons Public Domain Dedication waiver (http://creativeco mmons.org/publicdomain/zero/1.0/) applies to the data made available in this article, unless otherwise stated in a credit line to the data. 
[20] and also can be used as a supplementary means of public outreach and education [virtual reality (VR) [21] and augmented reality (AR) [22] in immersive museums, etc.].

Virtual archaeology is considered the second major application of 3D technology in $\mathrm{CH}$ [9]. Prior to this, the layout of the cultural relics and the information of the unearthed archaeological remains were recorded through notes, photos, and hand drawings. However, as the excavation procedure progresses, the soil is removed, and various remains are unearthed, which will cause the archaeological information to be irreversibly damaged. Although researchers can use the abovementioned materials to reconstruct each stage of the excavation procedure as fully as possible in their mind, it is inevitable that subjective deviation may be introduced in this process [23]. Via 3D technologies and geographic information systems (GIS), through graphic and metric information of high accuracy and quality, the process of excavation can be objectively recorded, visualized, represented, and reconstructed layer by layer $[24,25]$. At the same time, with the help of computer software, various 2D plans, sections, orthophotographs, etc., of interest also can be extracted whenever an issue arises or needs to be considered differently from before, which provides great convenience for subsequent research work [26].

The diversification of scanning methods and the upgrading of scanning technologies enable us to select appropriate scanning techniques $(\mathrm{CT} / \mu \mathrm{CT}$, structured light, laser scanner, motion sensor, photogrammetry/ SfM) for different materials of archaeological objects and capture more accurate topography, color, gloss, and other appearance characteristics data without intrusiveness [27, 28]. Meanwhile, the advancement of computer science makes it possible for virtual anastylosis (piecing together dismembered fragments of archaeological objects) $[29,30]$ and virtual reconstruction [31, 32]. In addition, the emergence and rapid development of digital manufacturing (additive manufacturing (AM), stereolithography (SLA), fused deposition modeling (FDM), material jetting (MJ), binder jetting (BJ), selective laser sintering (SLA), subtractive manufacturing $(\mathrm{SM})$, and computerized numerical control (CNC)digital sculpting) make it easier to obtain the missing parts of the archaeological objects [4]. The above three points enable 3D technologies to deeply participate in the entire workflow of conservation-restoration (CR); thus, virtual conservation has emerged. To date, with its assistance, more than 100 cases have been completed. The most common object materials were stone $[18,19,33-38]$ and ceramics [39-46]. This is followed by metal [14, 47], glass [40, 48], wood [49], murals [15], bone [50,51], wax [52], etc. Researchers directly obtain (or prepare molds and then recast to obtain [52]) the missing parts through digital manufacturing to achieve physical/aesthetic restoration (loss compensation) or print support structures to make the objects more stable (secondary support) $[15,53]$. In these cases, 3D technologies were mainly used to reduce frequent contact with the original that could entail certain risks of deterioration in the process of obtaining prostheses/ support structures. However, the prosthesis/support structure was ultimately connected to the original objects by bonding/welding/riveting, which may still bring some challenges related to the principles of $C R$ minimal intervention and reversibility.

Recently, researchers have begun to try new topics through virtual conservation that are difficult to achieve according to the conventional conservation-restoration procedure. For example, virtual restoration methods based on feature capture, quantitative characterization (Riemannian manifolds/skeleton lines), big data regression analysis, and calculation of predicted dimensions (in the case of complex construction where the geometric shape of the damaged area is unknown) were presented to solve the problem of the subjective experience influence of restoration personnel [54, 55]. An integrated mesh processing that comprises feature extraction, 3D print preview, feature preservation test, and shape enhancement was proposed to improve the perceptual quality of 3D printing [56]. The prostheses/presentation support with magnetic attraction/slots was specially designed and digitally manufactured to avoid subsequent problems of CR minimal intervention and reversibility that may be caused by bonding/welding/riveting with the original objects [57-59]. In particular, the microenvironment monitoring sensor also was designed and placed in the abovementioned magnetic prosthesis to achieve the preventive conservation of cultural relics [58]. It is foreseeable that there are still promising prospects for virtual conservation.

In this paper, we focused on a Black Ding bowl and obtained high-precision digital models of its 14 fragments through digital acquisition. With the help of virtual anastylosis, the attribution of the fragments was confirmed, and virtual reconstruction was carried out. Finally, we 3D printed a transparent reversible prosthesis with slots, which solved the contradiction between physical/aesthetic restoration and the most fundamental principles (integrity and authenticity of $\mathrm{CH}$, minimal intervention, reversibility, etc.) of the CR practice of this artifact. This work is an innovative attempt based on virtual conservation, which may have a profound impact on the conservation-restoration of ceramics, stone/glass artifacts, bronzes, irons, and other archaeological objects of hard material in the future. 


\section{Research aim}

Black Ding were rarely produced in Ding kilns. As Cao Zhao (曹昭) described in Ge Gu Yao Lun (格古要论, finished in Ming Dynasty), "There are Purple Ding with the color as purple, and there are Black Ding with the color as black like lacquer. Their bodies are all white, and their price is higher than that of White Ding". This reference shows the value and rarity of Black Ding.

Furthermore, Black Ding with gold tracing or gold past decoration are even more precious, and most of them are scattered abroad. According to the dates of the archaeological artifacts, Ding kiln porcelain decorated with metal foil appeared from approximately the late Northern Song Dynasty to the early Jin Dynasty [60]; it was mainly used for drinking tea by the royal families. Therefore, most of them are utensils, such as bowls. Very few bottles were found. By the end of the Southern Song Dynasty, porcelain decorated with gold foil was no longer produced [61].

According to the available evidence, there are a total of 9 objects of Black Ding decorated with gold tracing or gold past, of which only 4 objects are preserved in the museums. Two Black Ding bowls are in the Yamato Bunkakan collection in Osaka, Japan [62]. One Black Ding is in the MOA Museum of Art in Atami, Japan [63], and one is in the National Museum of Korea [64]. The rest are in the hands of some auction houses and private collectors [61]. Most of them have only pattern marks left, with the gold foil almost completely disappeared.

This study has been applied to an emblematic real case, the gold foil decorated Black Ding bowl collected by the Chifeng Museum of the Inner Mongolia Autonomous Region (Fig. 1). This bowl was broken into 14 fragments. The largest fragment retains a more complete pattern of gold foil, which should be the flowers and branches of a certain plant. Seven fragments still have some gold foil remnants. Thus, this Black Ding bowl is of great research significance and value.

The conservation-restoration process began in 2020 . Digital acquisition and digital modeling were proposed to obtain the visualization of the Black Ding bowl and thus facilitate the subsequent digital processing. Considering that the provenance of this bowl is donation and the relevant unearthed information is missing, virtual anastylosis

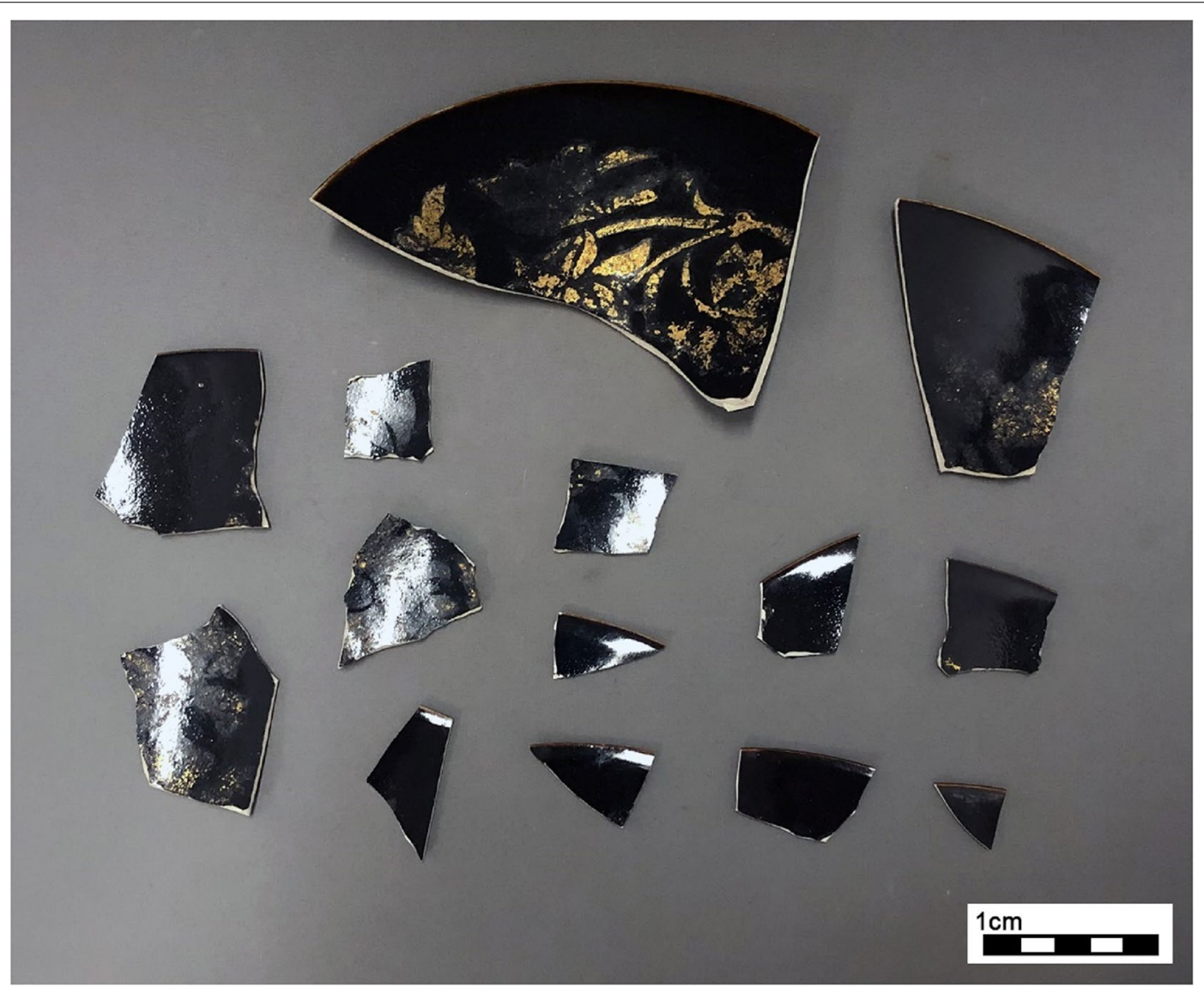

Fig. 1 The 14 fragments of the gold foil decorated Black Ding bowl (collected by Chifeng Museum of Inner Mongolia Autonomous Region) 
was carried out to confirm the attribution of the fragments and to reduce the frequent contact that may bring certain risks of deterioration during conventional manual CR practices. Finally, a transparent reversible prosthesis with slots was digitally manufactured to achieve physical/ aesthetic restoration and to follow the CR principles of the integrity and authenticity of $\mathrm{CH}$, minimal intervention, and reversibility to the utmost extent.

\section{Visualization of fragments}

Different scanning techniques work for different kinds of materials. Generally, objects with highly glossy surfaces are not suitable for photogrammetry and laser scanning methods because glossiness may result in more noise, which affects the accuracy and quality of the digital model [26]. However, in this article, since the focus we are concerned with is the morphology of the fractured interface, the interface (porcelain body) is made of matt material. Thus, the laser scanning method can display detailed results. In addition, the color of the glaze is black, and it became less reflective due to degradation. After comprehensive consideration, we finally chose laser scanning techniques to obtain the 3D data of the 14 fragments.
During digital acquisition, the portable scanner with seven blue laser lines (class II laser) AltairScan Elite ${ }^{\mathrm{TM}}$ (Fig. 2a) was used, which has two kinds of measurement modes (rapid/precise). The fragment to be scanned was placed in the center of a rotatable circular platform, on which the reflective points were pasted for calibration position (there were not any points pasted on the fragments). The precise measurement mode was selected, with a measuring speed of 450,000 times per second, a resolution of $0.02 \mathrm{~mm}$, a measuring accuracy of $0.01 \mathrm{~mm}$, a depth of field of $150 \mathrm{~mm}$, a measurement reference distance of $150 \mathrm{~mm}$, and a frame rate of 10-16 FPS. The platform was continuously rotated to obtain 3D data in all directions of the fragments (Fig. $2 \mathrm{~b}$ and Additional file 1: Fig. S1).

In the digital modeling phase, a workstation equipped with an Intel Xeon Platinum $826024 \mathrm{C} / 48 \mathrm{~T}$ CPU and one NVIDIA GTX 2080 Ti Graphics card with 4352 CUDA cores was used. The previously obtained 3D data (STL file) were exported to the CATIA V5R12 software, the complete state of the data was checked, and the noise was eliminated. Then, the 3D mesh was generated from the point clouds, and the mesh errors were checked and fixed. Finally, the visualization of the 14 fragments of the Black Ding bowl was obtained (Fig. 2c).

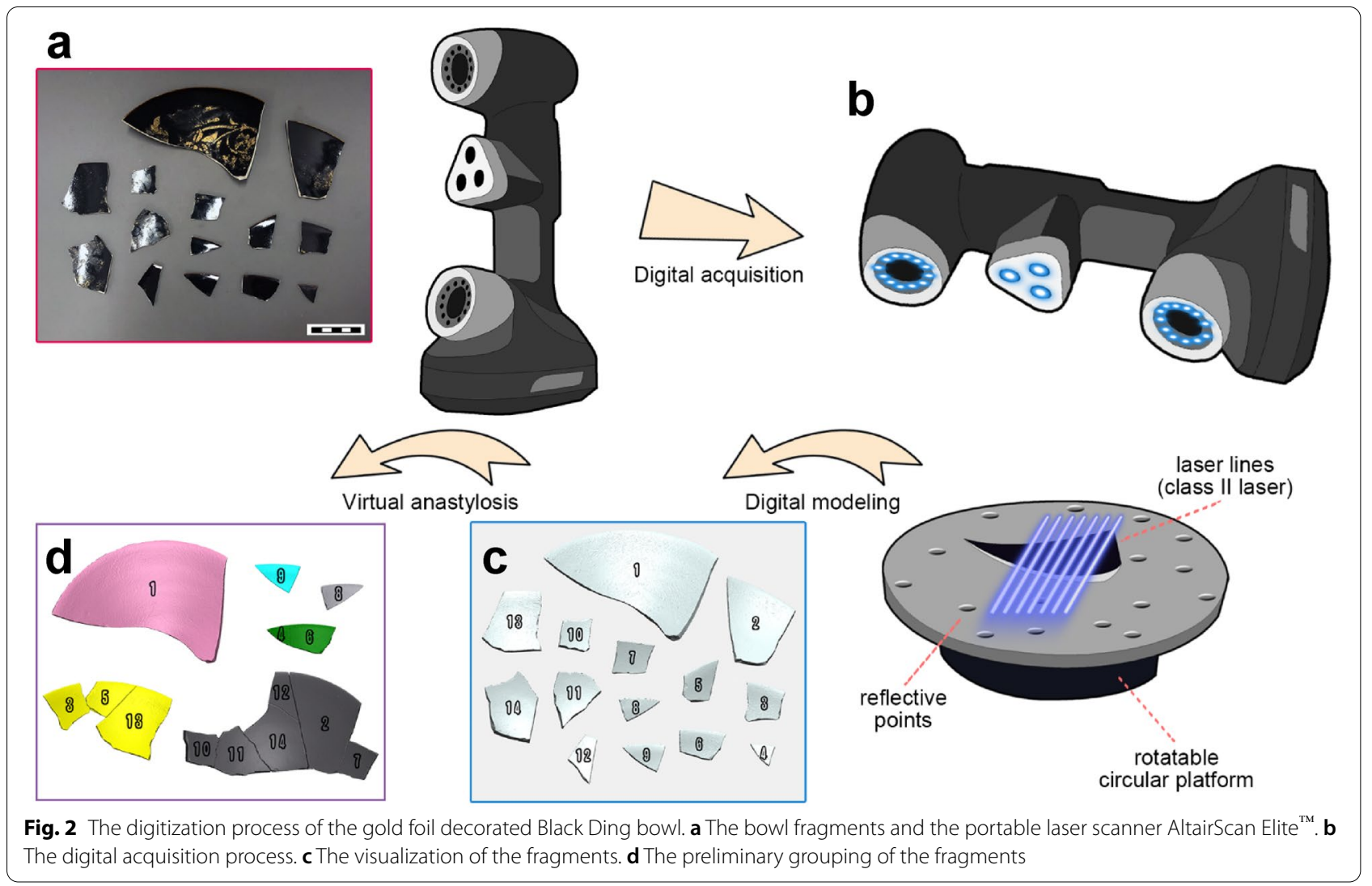




\section{Virtual anastylosis and reconstruction}

The purpose of virtual anastylosis is to reduce the possible abrasion of the fragments during the repeated manual anastylosis process. This was based on the high accuracy and quality of the digital model we acquired previously. The virtual anastylosis was finished in the Geomagic Desing software by means of an automatic computerized fit and calculation of the morphology of the fractured interface and the thickness of the fragments (Additional file 1: Fig. S2). Eventually, virtual anastylosis allowed us to preliminarily group the 14 fragments (Fig. 2d) into Group 1 (G.1, Numbers 2, 7, 10, 11, 12, and 14), Group 2 (G.2, Numbers 3, 5, and 13), Group 3 (G.3, Numbers 4 and 6), and three separate fragments (Numbers 1, 8, and 9).

We should note here that the provenance of this Black Ding bowl is a donation, and therefore, the excavation information is unknown, so there is no absolute evidence that all the fragments belong to the same artifact. Thus, we need to prove this, and the high-precision digital models also provided us with the possibility, mainly by calculating and comparing a specific physical feature of the artifact. For example, a previous comparison of the consistency of the ornamentation and the width between the south Chimi (ridge-end tile) and the north Chimi from the Wangheungsa temple site in Korea revealed that the two did not belong to the same Chimi [43].

Considering that all six groups of fragments (G.1 to G.3 and Nos. 1, 8, 9) have a rim part, we intended to obtain the circumference of the entire bowl by extrapolating the rim part and determine their attribution by comparing the radius (Additional file 1: Figs. S3, S4). The results showed that the errors of the remaining groups were within $1 \%\left(\mathrm{r}_{\mathrm{g} .1}=91.61 \mathrm{~mm}, \mathrm{r}_{\mathrm{g} .2}=92.25 \mathrm{~mm}\right.$, $\left.\mathrm{r}_{\mathrm{g} .3}=92.94 \mathrm{~mm}, \mathrm{r}_{\mathrm{no} .1}=91.32 \mathrm{~mm}, \mathrm{r}_{\mathrm{no} .8}=91.55 \mathrm{~mm}\right)$, except for the large difference in the extrapolation radius of No. $9\left(r_{\text {no. } 9}=96.30 \mathrm{~mm}\right.$ and the error reached $\left.5 \%\right)$. Therefore, we can basically conclude that the vast majority of these fragments should belong to the same piece of Black Ding bowl.

The next step involved the virtual restoration of this artifact. We noticed that three groups of fragments (G.1, G.2, and No. 1) occupied most of the volume of the Black Ding, so to complete the restoration, it was necessary to first determine the relative positions of these three groups of fragments. The results showed that there was only one possible relative position of these three groups of fragments (Fig. 3a, b). Among the three remaining groups, G.3 can be placed only in the larger vacant position of G.1, while No. 8 can be placed only in the smaller vacant position of G.1 (Fig. 3c, because No. 9 does not fit). In contrast, there were two possibilities for the placement of No. 9 relative to G.2. In the first scenario, all the fragments were placed in a tighter manner
(Fig. 3d), with points of contact between No. 1 and No. 7 (spot A), No. 1 and No. 3 (spot B), and No. 9 and No. 10 (spot $C$ ). The thickness of the fragments at the locations of these contact points was examined, and spot $B$ (No. $1_{B}=3.315 \mathrm{~mm}$, No. $3_{B}=2.475 \mathrm{~mm}$ ) had a significant difference, while spot A (No. $1_{\mathrm{A}}=2.542 \mathrm{~mm}$, No. $\left.7_{\mathrm{A}}=2.627 \mathrm{~mm}\right)$ and spot $\mathrm{C}\left(\right.$ No. $9_{\mathrm{C}}=2.342 \mathrm{~mm}$, No. $10_{C}=2.464 \mathrm{~mm}$ ) did not (Additional file 1: Fig. S5). From this, it could be concluded that there is only one final and relatively reasonable placement of the fragments, and the location of the residual marks corresponding to the broken bottom of this bowl also is the most appropriate (Fig. 3e and Additional file 1: Fig. S6).

As we have mentioned before, the attribution of fragment No. 9 cannot yet be directly confirmed based on the radius result obtained from extrapolation, while we cannot currently determine the absolute locations of all 14 fragments and cannot exclude the possibility of new fragments discovered in the future. Thus, if the physical/ aesthetic restoration (loss compensation) of this artifact is carried out according to conventional manual CR practices, it may create subjective speculative deviation and cause extremely serious and irreversible harm to the artifact. On balance, we decided to use a reversible prosthesis to complete the restoration of this Black Ding bowl. The design concept of this prosthesis originated from an earlier application of a presentation support with slots (secondary support) [57]. However, due to the limitations of the accuracy of digital model/3D printing at that time, this method was not widely promoted. In this paper, we designed a reversible prosthesis with slots (Fig. 4) in the same shape as the artifact with the benefit of a highprecision digital model and more advanced 3D printing equipment and achieved a nondestructive and reversible process by physically embedding the fragments with the prosthesis through the slots (without using any form of adhesive) while reconstructing the full shape of the artifact.

\section{Material performance test}

Considering the aesthetics of the final restoration, we had high requirements for the accuracy of the $3 \mathrm{D}$ printing method and the details of the output of this reversible prosthesis, so here we chose a stereolithographic printer (SLA method) for printing [58]. At the same time, we also needed to focus on the mechanical properties of the printing material (in relation to the stability of the artifact), stain resistance, and aging resistance. In general, we still needed to consider the interaction of the printing material's aging product (volatile organic compounds, VOCs) in contact with the original artifact [65-67]. However, because this artifact is well preserved (no persistent disease) and because porcelain is not as sensitive 

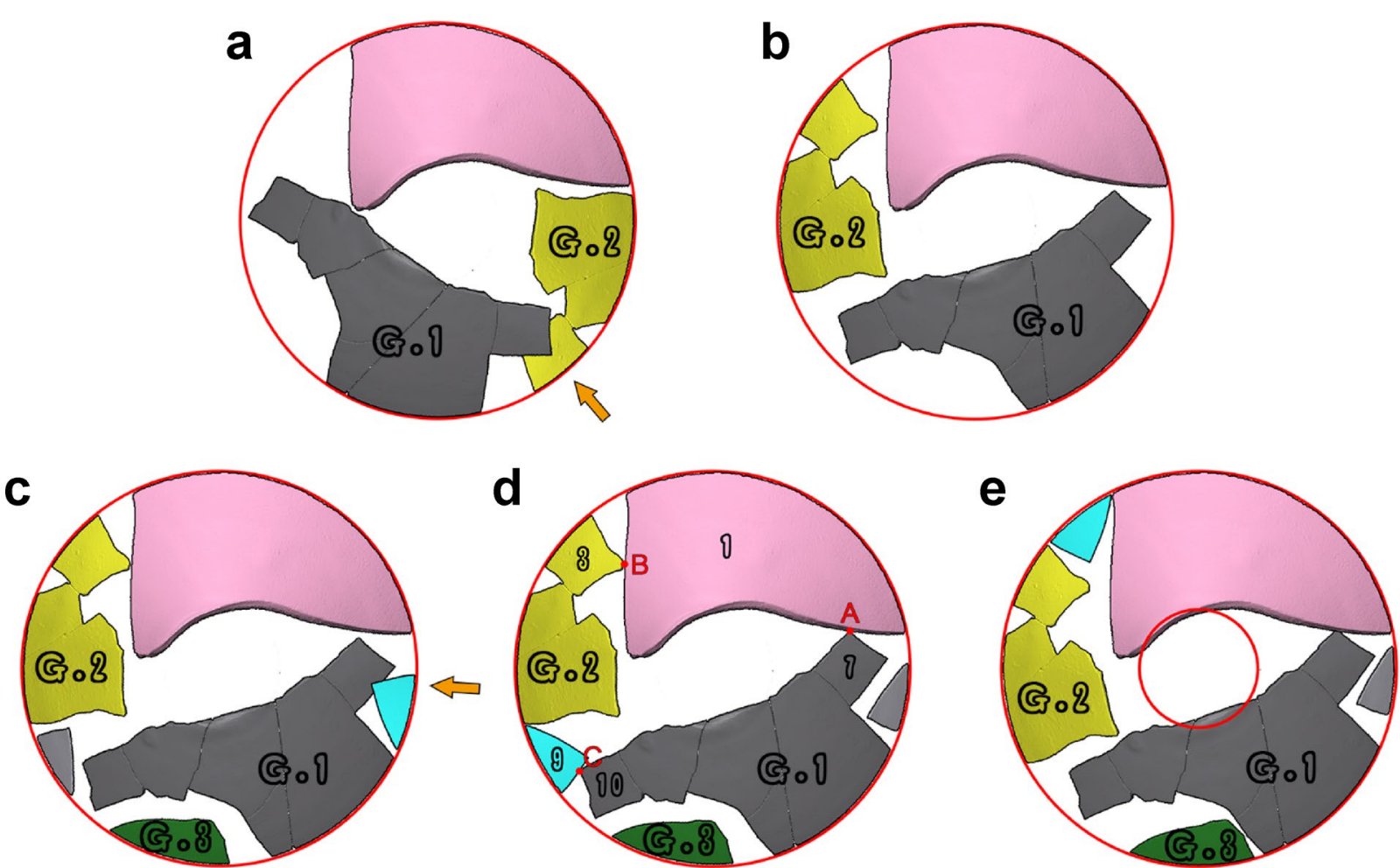

Fig. 3 The virtual anastylosis process of the fragments. a It is not feasible to place the Group 1, Group 2, and Number 1 fragments into the relative position shown in the scheme. b The relative positions of the Group 1, Group 2, and Number 1 fragments are rationalized. c The Number 9 fragment conflicts with the location of Group 1. d There is a thickness difference between the Number 1 and Number 3 fragments at spot B. e The only final and relatively reasonable placement of the fragments

to VOCs as metals, lacquerwares, etc., we did not conduct further specific experimental studies on VOCs in this work to simplify our workflow.

We initially chose two printing materials, an ivory photopolymerization resin and a transparent photopolymerization resin, and designed experiments to compare the performance with the materials commonly used in conventional manual CR procedures, plaster and epoxy resin.

\section{Experimental}

\section{Sample preparation}

There were two sizes of samples: dumbbell-shaped samples and round samples (Additional file 1: Fig. S7). The dumbbell-shaped samples were $10 \mathrm{~cm}$ long, $5 \mathrm{~mm}$ thick, $25 \mathrm{~mm}$ wide at both ends, and $15 \mathrm{~mm}$ in the middle. The round samples were $78 \mathrm{~mm}$ in diameter and $7.5 \mathrm{~mm}$ thick.

The samples were prepared differently for different materials:

The ivory photopolymerization resin samples were directly $3 \mathrm{D}$ printed by a Stratasys $\mathrm{J} 835^{\mathrm{TM}}$ stereolithographic printer (printing accuracy of $14 \mu \mathrm{m}$ ), and the material used was VeroWhitePlus ${ }^{\mathrm{TM}}$.

The transparent photopolymerization resin samples were directly $3 \mathrm{D}$ printed by a Stratasys $\mathrm{J} 850^{\mathrm{TM}}$ stereolithographic printer (printing accuracy of $14 \mu \mathrm{m}$ ), and the material used was VeroUltraClear ${ }^{\mathrm{TM}}$.

The plaster samples were made from preprepared molds, and the material used was a $600 \mathrm{~g}: 168 \mathrm{~g}$ mixture of Shiseido HARD STONE ${ }^{\mathrm{TM}}$ plaster ( $\alpha$-type superhard dental plaster, curing temperature of $21-25^{\circ} \mathrm{C}$ ) and deionized water (specific resistance of $18.25 \mathrm{M} \Omega \mathrm{cm}$ ).

The epoxy resin samples were made from preprepared molds, and the material used was a 1:2 mixture of epoxy resin (component $\mathrm{A}: \mathrm{B}=3: 1$, purchased from Guangzhou Shunyicheng Technology Co., Ltd., China) and calcium carbonate powder $\left(\mathrm{CaCO}_{3}, 1250\right.$ mesh, purchased from Shanghai Meryer Chemical Technology Co., Ltd., China).

\section{Characterization methods}

Three-point bending tests were carried out by a Qualitest QT-01 ${ }^{\mathrm{TM}}$ Universal Testing Machine $\left(\mathrm{P}_{\text {sensor }}=1000 \mathrm{~N}\right.$, $\mathrm{l}=45 \mathrm{~mm}, \mathrm{~b}=15 \mathrm{~mm}, \mathrm{~h} \approx 5 \mathrm{~mm})$. Drop-weight impact tests were carried out by a DongRi DR-7017 ${ }^{\mathrm{TM}}$ Steel Ball 

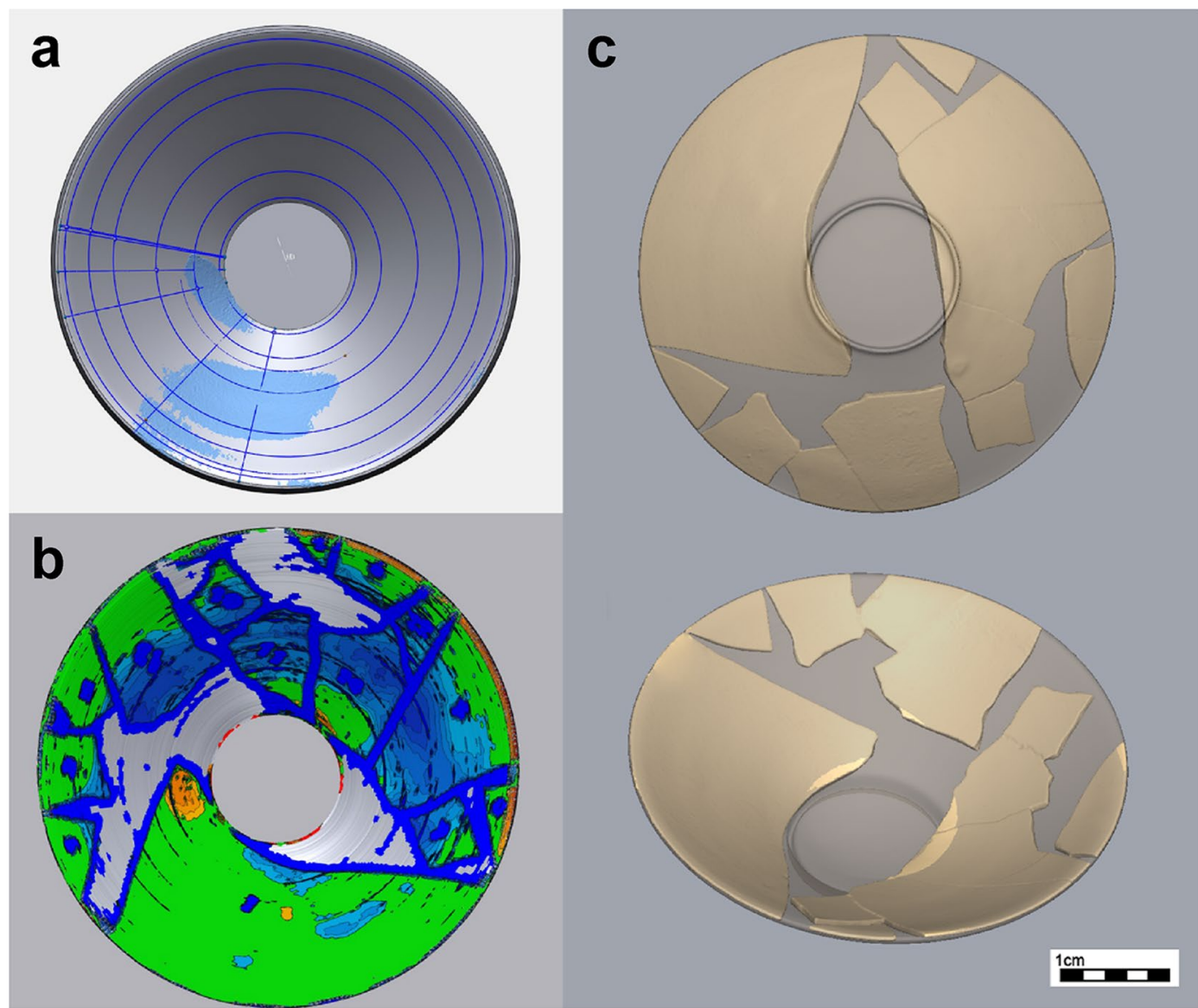

Fig. 4 The design process of the reversible prosthesis. a Based on the curvature data of the fragments, the prototype data of the artifact were simulated and recovered. $\mathbf{b}$ The location and volume parameters of the fragments were tested for fit by comparison with the data of the restored prototype bowl. After passing the test, the space for the fragments was cut out. $\mathbf{c}$ The design effect picture of the reversible prosthesis

Impact Testing Machine $(\mathrm{M}=9 / 20 / 32 / 55 / 120 / 225 / 378$ $1535 \mathrm{~g}, \mathrm{H}=100 \mathrm{~cm})$. Microscopic images were taken by a Shangguang SX- $6^{\mathrm{TM}}$ stereomicroscope, and color difference analysis was conducted simultaneously with a $3 \mathrm{NH}$ $\mathrm{SC}-10^{\mathrm{TM}}$ chromatic aberration analyzer.

\section{Sample aging process}

UV aging of the material was carried out in a Guangdong SIRUI LX-340 ${ }^{\mathrm{TM}}$ light aging test chamber, which was equipped with two UVA lamps $(\mathrm{L}=1200 / 40 \mathrm{~W}, \lambda \approx 315-$ $400 \mathrm{~nm}$, service life of more than $1600 \mathrm{~h}$ ). The samples were placed in the test chamber to accelerate aging for $50 / 100 / 200 / 500 \mathrm{~h}$.

\section{Results and discussion \\ Mechanical properties of the materials}

Three-point bending tests were used to simulate the various forces to which the artifacts may be subjected during preservation and transportation to assess the mechanical properties of the materials.
The dumbbell-shaped samples were used in the tests. The maximum load that the sensor can support is $1000 \mathrm{~N}$ ( $\left.\mathrm{P}_{\text {sensor }}\right)$, and the load spam (l) is $45 \mathrm{~mm}$. The width (b) of the samples is $15 \mathrm{~mm}$, and the thickness (h) of the sample is approximately $5 \mathrm{~mm}$. A constantspeed downpressing mode was chosen during the tests (speed $=1 \mathrm{~mm} / \mathrm{min}$ ). When the instantaneous load reached $1 \%$ of $\mathrm{P}_{\text {sensor }}$, the data began to be recorded, and when the instantaneous load (P) attenuated 30\% of the maximum instantaneous load $\left(\mathrm{P}_{\max }\right)$, the tests stopped. Finally, the load-displacement curves $(\mathrm{P}-\mathrm{x})$ of the samples were obtained.

To better compare the mechanical strength and brittleness between different materials, the maximum bending strength $\left(\sigma_{\mathrm{bb}}\right)$ and elastic modulus $\left(\mathrm{E}_{\mathrm{b}}\right)$ of the samples were calculated based on the $\mathrm{P}-\mathrm{x}$ curves (Additional file 1: Table S1) with the help of MATLAB (Additional file 1: Table S2). The equations are as follows $[68,69]$. 


$$
\begin{aligned}
\sigma_{b b} & =\frac{3 P_{\max } \times l}{2 b h^{2}}, \\
E_{b} & =\frac{l^{3}}{4 b h^{3}} \times\left(\frac{\Delta P}{\Delta f}\right),
\end{aligned}
$$

where $\mathrm{f}$ is the deflection and $\frac{\Delta P}{\Delta f}$ is the slope of the $\mathrm{P}-\mathrm{f}$ curve. When the deformation of the samples is not too large, we consider $\mathrm{f}=\mathrm{x}$ to simplify the model. Other physical quantities have been explained above. The calculation results of $\sigma_{\mathrm{bb}}$ and $\mathrm{E}_{\mathrm{b}}$ are shown in the histogram in Fig. 5.

From the calculation results of $\sigma_{\mathrm{bb}}$, the ivory photopolymerization resin material has the highest mechanical strength, slightly higher than the transparent photopolymerization resin, and significantly higher than the plaster and epoxy resin. Meanwhile, from the calculation results of $E_{b}$, plaster is the most brittle, epoxy resin is second, and ivory photopolymerization resin and transparent photopolymerization resin are third and fourth, respectively. In general, the mechanical properties of the two photopolymerization resin materials are significantly better than those of the conventional restoration materials in terms of bending resistance and material toughness, which makes the artifacts less susceptible to damage under the same force.

Drop-weight impact tests also were used to evaluate the mechanical properties of the materials when subjected to a possible impact. The round samples were used in the tests. The weight of the drop hammer (M) is $9 / 20 / 32 / 55 / 120 / 225 / 378 / 535 \mathrm{~g}$. The electromagnet was fixed at a specific height $(\mathrm{H}=100 \mathrm{~cm})$, and the

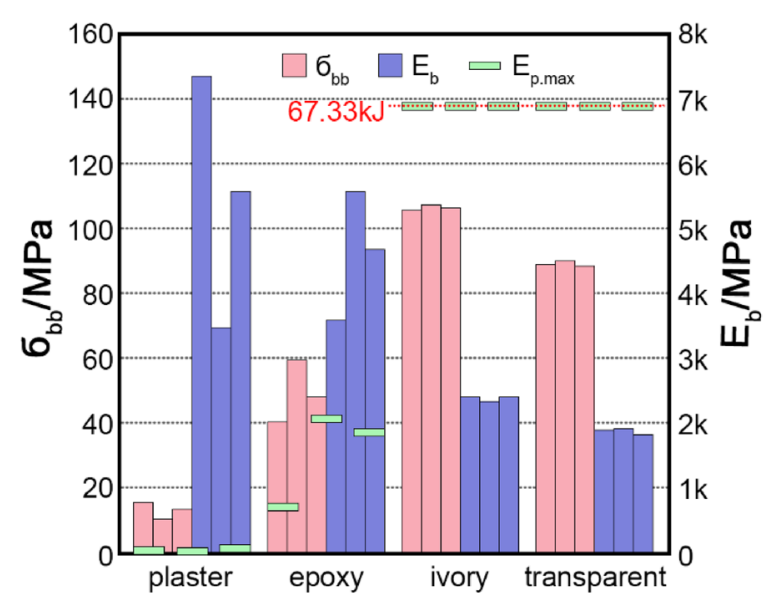

Fig. 5 The mechanical properties test results of the 3D printing materials ( $\sigma_{b b}, E_{b}$, and $\left.E_{p . m a x}\right)$. From the results, the two photopolymerization resin materials have excellent mechanical strength and impact resistance. In comparison, the ivory photopolymerization resin is superior drop hammer was attached to it. The sample was placed directly below the electromagnet. When the test began, the electromagnet was disconnected, and the drop hammer fell in free fall and hit the sample in the center (the drop point could be located by laser). The hammer was selected in order from small to large, and the experiment was repeated 5 times for the same weight. Finally, the cumulative impact potential energy $\left(E_{p \cdot \max }\right)$ of the sample was recorded when it was broken. The equation is as follows, and the results also are shown in Fig. 5.

$$
E_{p . \max }=\sum M g H
$$

From the results, it appears that the impact resistance of the plaster was extremely weak, the epoxy was slightly stronger, and the two photopolymerization resins reached a maximum of $67.33 \mathrm{~kJ}$. It should be noted, however, that at the end of the experiment, no cracks or fractures occurred on the surface of any of the photopolymerization resin samples; in fact, one of the samples was subjected to approximately 30 repeated impacts with a $500 \mathrm{~g}$ drop hammer and remained intact, indicating that the impact resistance of the two photopolymerization resins was extremely good.

\section{Stain resistance of the materials}

According to past experience, in the process of preservation after CR practice, the artifacts are easily contaminated by dust or marks made for museum collection needs, both of which are difficult to remove. Therefore, cleaning tests were performed for these common sources of contamination to assess the stain resistance of the materials.

We selected three kinds of contaminants, dust, oilbased markers, and water-based markers, and evenly applied them to the samples. After the contaminants were completely dry, we cleaned these materials with different solvents (pure water, surfactants, ethanol, or acetone), using cotton swabs as cleaning tools, until the color of the contaminants could not be further wiped off by the solvent-soaked swabs. Color difference analysis, using the CIE L*a*b* system [70], was carried out, and the $\triangle E$ value was used to quantitatively characterize the chromatic aberration between the cleaned sample surface and the control group (not coated with any contaminant). To avoid systematic errors, we randomly selected three points in the cleaned area, obtained their $\Delta \mathrm{E}$ directly and took the average value. The comparison images of the samples before and after cleaning are shown in Fig. 6 with the $\Delta \mathrm{E}$ results. In such cases, a smaller $\Delta \mathrm{E}$ indicates a better cleaning effect and a higher stain resistance of the material, and vice versa. 

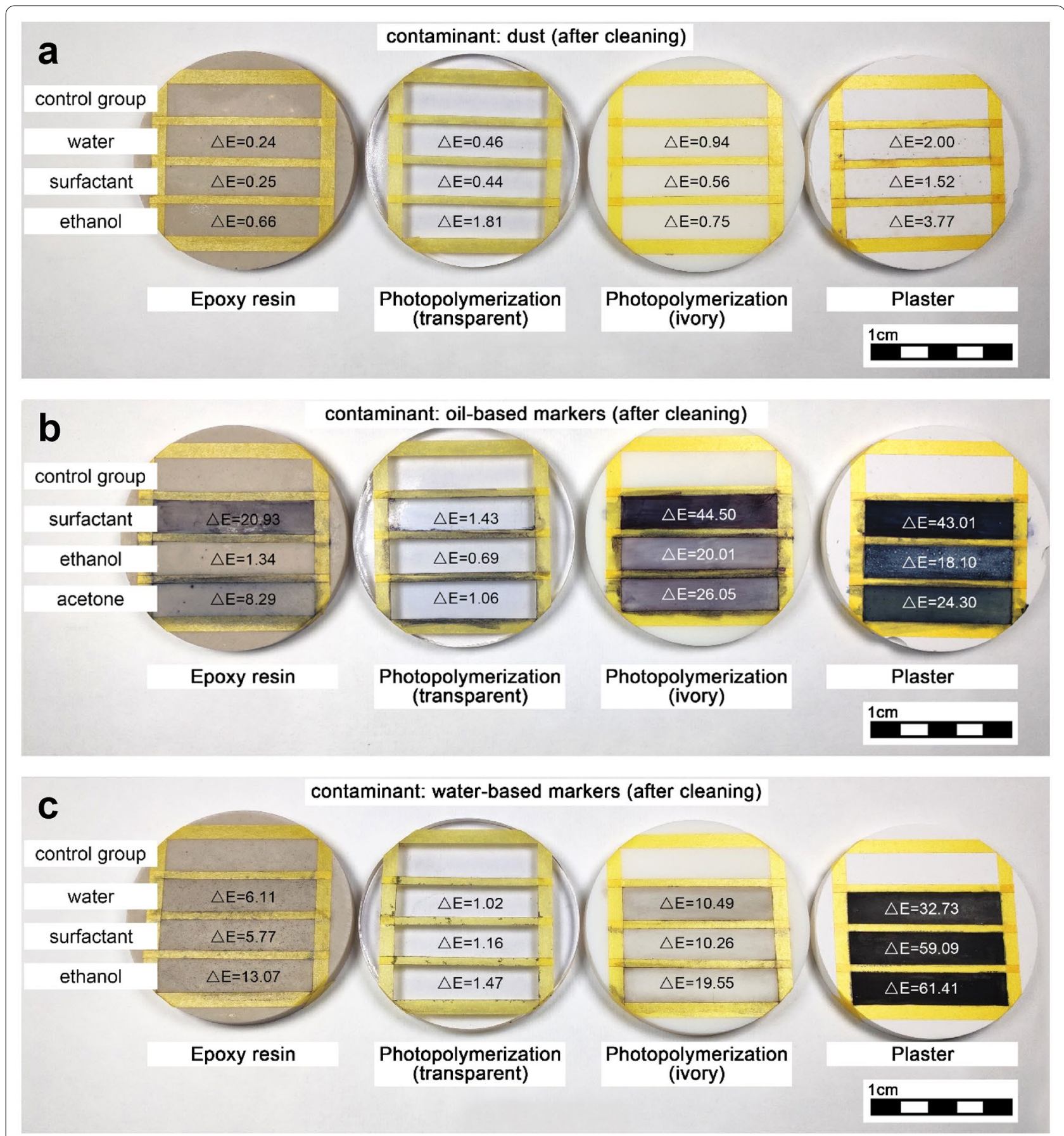

Fig. 6 The stain resistance test of the 3D printing materials $(\Delta \mathrm{E})$. Three kinds of contaminants, a dust, $\mathbf{b}$ oil-based markers, and $\mathbf{c}$ water-based markers, were applied to the round samples and then cleaned with different solvents. From the results, the stain resistance of the transparent photopolymerization resin was significantly higher than that of the other materials

The results showed that the transparent photopolymerization resin material had an excellent stain resistance in the face of all three contaminants, with epoxy resin and ivory photopolymerization resin being next, and plaster the worst. From the microscopic observation (Additional file 1: Fig. S8), the high porosity of the plaster surface made it easy for oil-based and water-based markers to penetrate into it and almost impossible to remove. Epoxy resin also had a small number of holes formed during the curing process, which affected the aesthetics of the 
cleaned surface. For transparent photopolymerization resin, although there were some obvious scratches under microscopic observation, the morphology and color changes were almost imperceptible to the naked eye.

\section{Aging resistance of the materials}

In general, photopolymerization resins are less resistant to yellowing, especially under long-term exposure to UV light, which may affect the performance of the materials and thus the stability of the restored artifacts. Therefore, we conducted accelerated UV aging of the materials and tested and compared the changes in the mechanical properties of the materials before and after aging.

As a result, both photopolymerization resins yellowed severely, and UV exposure greatly affected their aesthetic appearance (Fig. 7). However, for the mechanical properties (Additional file 1: Fig. S9), the effects of UV aging did not significantly affect the materials, in terms of maximum bending strength $\left(\sigma_{\mathrm{bb}}\right)$, elastic modulus $\left(\mathrm{E}_{\mathrm{b}}\right)$, or impact resistance $\left(\mathrm{E}_{\mathrm{p} \text {.max }}\right)$.

\section{Transparent reversible prosthesis}

Because of its excellent mechanical strength, impact resistance, and stain resistance, we finally decided to use the transparent photopolymerization resin material (VeroUltraClear $^{\mathrm{TM}}$ ) to complete the restoration of this Black Ding bowl. Although this material may undergo serious yellowing under UV exposure, it can be avoided by improving the subsequent preservation environment (such as the addition of an ultraviolet filter to the lamps).

An SLA Stratasys $1850^{\mathrm{TM}}$ stereolithographic printer with a resolution of $14 \mu \mathrm{m}$ for printing the prosthesis was used. After optimization of the model, printing, elimination of residual resin, UV treatment, and fine-tuning, the transparent reversible prosthesis was carried out. The overall height of the prosthesis was $52.62 \mathrm{~mm}$, the maximum radius (rim of the bowl) was $93.38 \mathrm{~mm}$, and the minimum radius (bottom of the bowl) was $31.02 \mathrm{~mm}$.

Subsequently, each piece of the fragment was placed into the appropriate slot on the prosthesis, and the restoration of this artifact was finally finished (Fig. 8 and Additional file 1: Fig. S10).

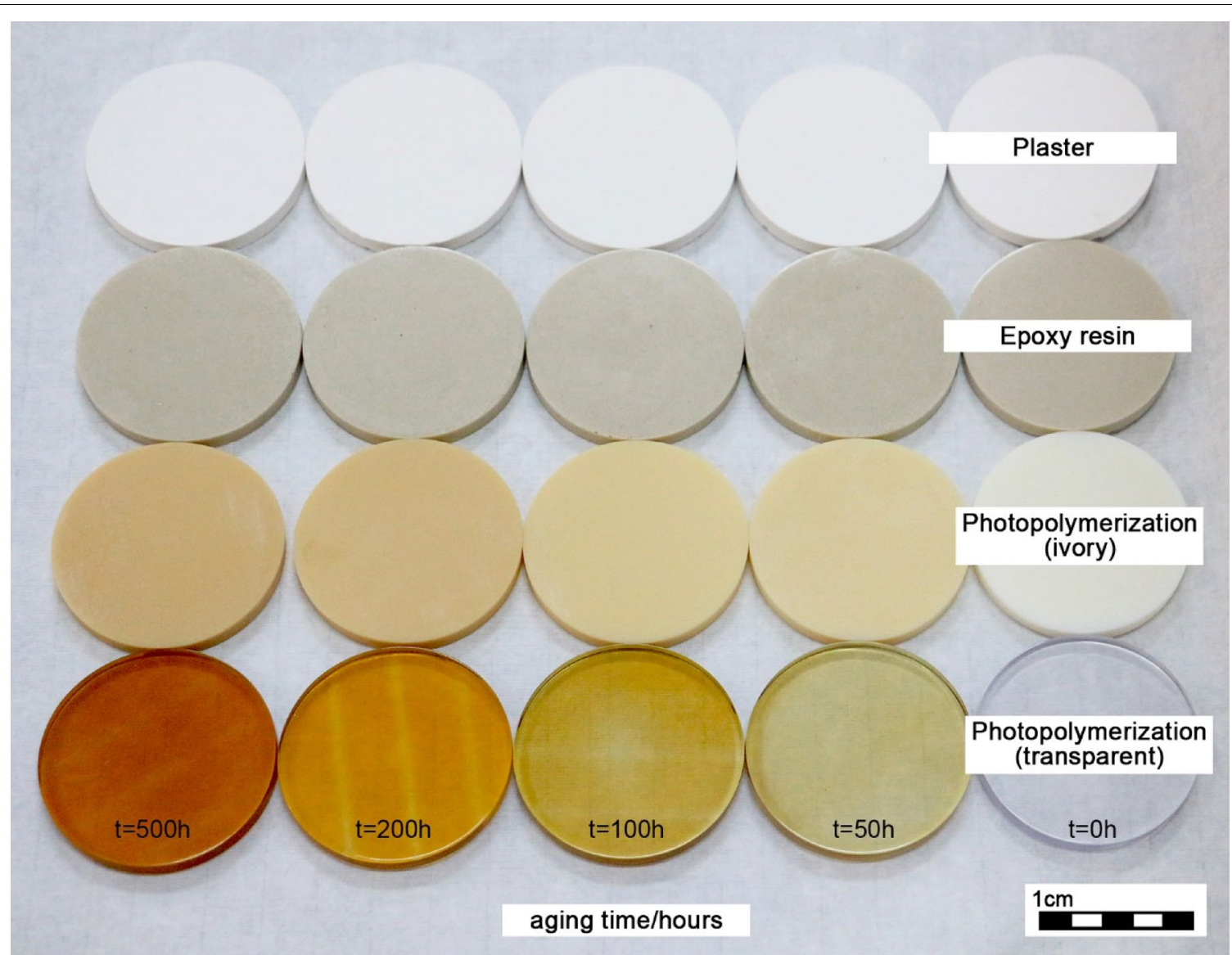

Fig. 7 The UV aging resistance test of the 3D printing materials. From the results, the yellowing resistance of the two photopolymerization resin materials was poor. However, the yellowing might be avoided by improving the subsequent preservation environment 


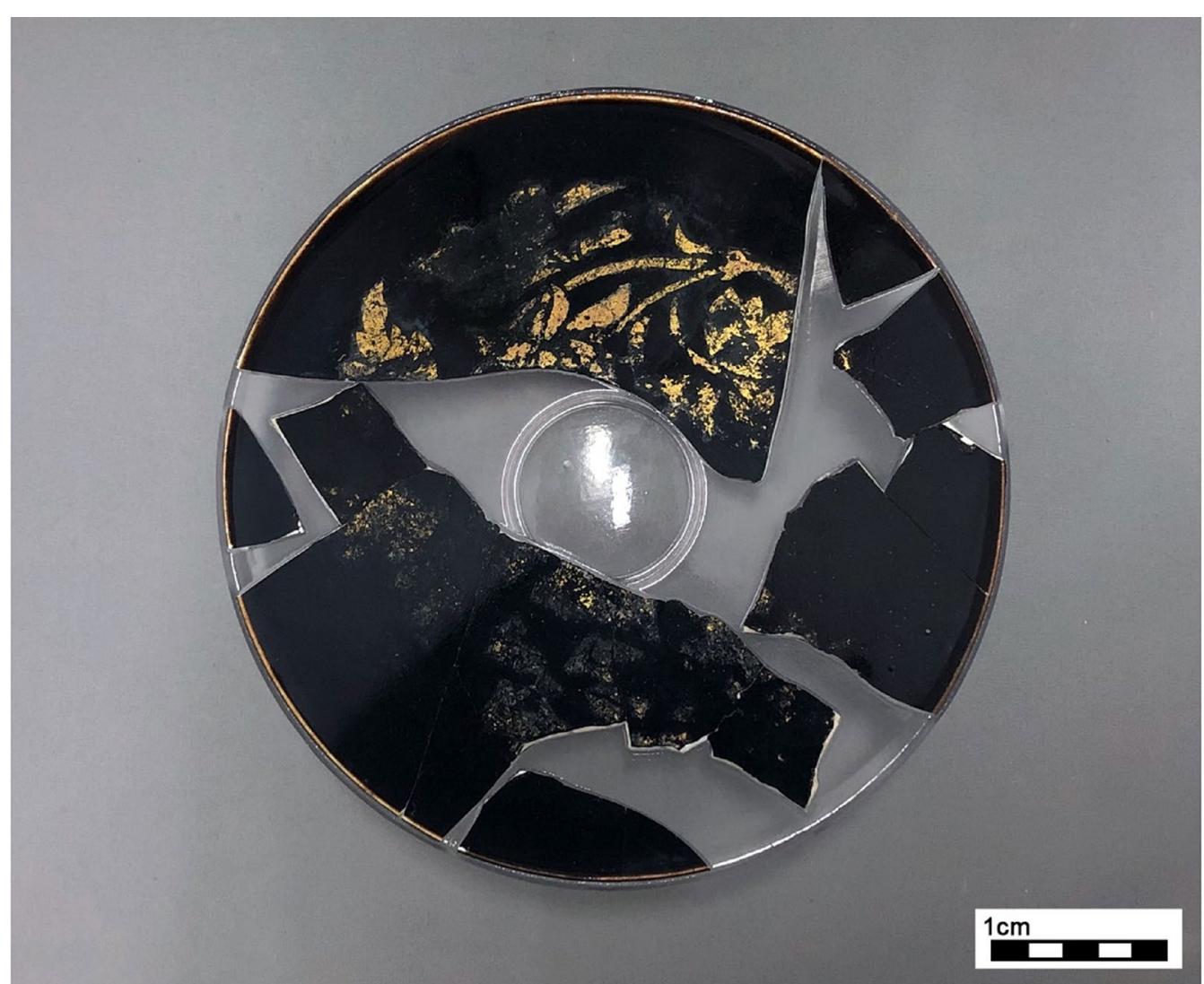

Fig. 8 A view of the conservation-restoration result of this gold foil decorated Black Ding bowl

The application of a transparent reversible prosthesis has the following advantages:

- The shape and ornamental information of this highly valuable artifact were completely reproduced. Both its physical restoration and aesthetic restoration were achieved.

- The principle of minimal intervention in the CR practice was maximized. The artifact was touched only during the digital acquisition process, greatly reducing the frequent contact that may bring certain risks of deterioration.

- There was no dispute about authenticity, and there were no problems of subjective speculative deviation during the $\mathrm{CR}$ practice, greatly retaining space for subsequent argumentation.

- Theoretically, with "unlimited reversibility", the prosthesis can be remanufactured and replaced at any time.

\section{Conclusion}

In this paper, we restored a gold foil decorated Black Ding bowl from the collection of the Chifeng Museum of the Inner Mongolia Autonomous Region through a virtual conservation approach. With the innovative application of a transparent reversible prosthesis, the contradiction between the conservation-restoration procedure and the CR principles (authenticity of cultural heritage, minimal intervention, usage of reversibility, etc.) was resolved while achieving the physical restoration and aesthetic restoration of this artifact.

This work is quite representative and forward-looking, but there is still a long way to go before this method can be widely promoted. For example, in this paper, we dealt with a simple artifact, but how can a similar method be used for the restoration of a more complex artifact with a more complex shape? In virtual conservation work, technology outsourcing is a common practice that provides us with great convenience, including 3D technologies, 
but also brings challenges, such as technical barriers. The performance, composition, and structure of printing materials is often unknown, which makes us largely lose the initiative of technology and material research, while not being conducive to cost control. In our work, we conducted an exemplary assessment of the performance of two photopolymerization resin materials; however, for different materials, the material properties that might affect the restoration and subsequent preservation of archaeological objects may be different. Can we conduct a more comprehensive performance assessment of the digital manufacturing materials available in the market today in the context of CR practice and accordingly develop new 3D printing technologies and printing materials applicable to our work? These are the questions that need to be addressed. Only when these issues are resolved can our work be better promoted and 3D technologies be better applied to $C R$ practice.

\section{Supplementary Information}

The online version contains supplementary material available at https://doi. org/10.1186/s40494-022-00646-0.

Additional file 1: Figure S1. The steps and procedure of the digital acquisition (take No. 1 as an example). Figure S2. The steps and procedure of the virtual anastylosis (take Nos. 4 and 6 as an example). Figure $\mathbf{S 3 .}$ The steps and procedure of extrapolating the rim part and obtaining the radius of the fragments (take No. 1 as an example). Figure S4. The circumference of the entire bowl obtained by extrapolating the rim part and the radius value calculated by circumference. Figure $\mathbf{S 5}$. The thickness of the contact points measured through the digital models of the fragments. Figure $\mathbf{S 6}$. Traces of the broken bottom remaining on the fragments. Figure S7. Two sizes of the samples, dumbbell-shaped samples and round samples. Figure $\mathbf{S 8}$. The microscopic observation of the sample surface after cleaning. Figure S9. Results of the mechanical property tests. Samples of each materials (plaster, epoxy-epoxy resin, ivory-ivory photopolymerization resin, and transparent-transparent photopolymerization resin) were respectively accelerated UV aging for 50/100/200/500 h. Figure S10. The conservation-restoration result of the gold foil decorated Black Ding bowl. (a) Transparent reversible prosthesis printed by SLA STRATASYS $\mathrm{J} 850^{\mathrm{TM}}$ stereolithographic printer. (b) Side view of the conservation-restoration result. Table S1. The maximum bending strength $\left(\sigma_{b b}\right)$ and elastic modulus $\left(E_{b}\right)$ of the samples calculated based on the $P$ - $x$ curves by MATLAB. Table S2. MATLAB code of P-x curves extrapolation.

\section{Acknowledgements}

We thank Ms. Sun, Engineer Wen, and Engineer Qin from YunTian Conservation \& Restoration Technology Co., Ltd., for their outstanding technical support on 3D technologies.

\section{Authors' contributions}

$S L$ developed the concept, performed the experiments, and analyzed the experimental data. YT contributed to the material performance tests and analyzed the data. XW and $Y Z$ prepared the samples and contributed to the three-point bending tests. $B Q$ contributed to the drop-weight impact tests and the sample aging process. ZX fitted the experimental data of the threepoint bending tests with the help of MATLAB. SL and YT wrote the manuscript. $\mathrm{HZ}$ and $\mathrm{DH}$ designed and directed the project. All authors read and approved the final manuscript.

\section{Funding}

This research received no external funding.
Availability of data and materials

Data will be available on request.

\section{Declarations}

\section{Competing interests}

The authors declare no competing interests.

\section{Author details}

${ }^{1}$ The International Center for Chinese Heritage and Archaeology, School of Archaeology and Museology, Peking University, Beijing 100871, China. ${ }^{2}$ Chifeng Museum, Chifeng 024050, Inner Mongolia Autonomous Region, China. ${ }^{3}$ Institute for Advanced Study, Tsinghua University, Beijing 100084, China.

Received: 3 November 2021 Accepted: 7 January 2022

Published online: 24 January 2022

\section{References}

1. Dunn SM, Keizer RL, Yu J. Measuring the area and volume of the human body with structured light. IEEE Trans Syst Man Cybern. 1989;19:1350-64.

2. Sato I, Sato Y, Ikeuchi K. Acquiring a radiance distribution to superimpose virtual objects onto a real scene. IEEE Trans Vis Comput Graph. 1999:5:1-12.

3. Gerig LH, El-Hakim S, Szanto J, Malone S, Salhani DS, Yaychuk T, Girard A. 450A vision-based patient position monitoring tool for radiotherapy. Radiother Oncol. 1996;40:S116-S116.

4. Acke L, De Vis K, Verwulgen S, Verlinden J. Survey and literature study to provide insights on the application of 3D technologies in objects conservation and restoration. J Cult Herit. 2021;49:272-88.

5. Cortelazzo GM, Marton F. 3D modeling for cultural heritage applications. In: Proceedings of the 2nd Intern. congress on science and technology for the safeguard of cultural heritage in the Mediterranean basin, Paris; 1999.

6. Beraldin JA, Blais F, Cournoye L, Rioux M, ElHakim SH, Rodella R, Bernier F, Harrison N. Digital 3D imaging system for rapid response on remote sites. In: Second international conference on 3D digital imaging and modeling, Ottawa; 1999

7. Levoy M. The digital Michelangelo project. In: Proceedings of the second international conference on 3D digital imaging and modeling, Ottawa; 1999.

8. The London Charter. The London Charter for the computer-based visualisation of cultural heritage; Draft 2.1 of 7 February 2009. London: King's College London; 2009.

9. Carrillo Gea JM, Toval A, Fernández Alemán JL, Nicolás J, Flores M. The London Charter and the Seville Principles as sources of requirements for e-archaeology systems development purposes. Virtual Archaeol Rev. 2013:4:205-11.

10. Lopez LV. Authenticity and realism: virtual vs physical restoration. Cambridge: McDonald Institute; 2018.

11. Zlot R, Bosse M, Greenop K, Jarzab Z, Juckes E, Roberts J. Efficiently capturing large, complex cultural heritage sites with a handheld mobile 3D laser mapping system. J Cult Herit. 2014;15:670-8.

12. Barton J. 3D laser scanning and the conservation of earthen architecture: a case study at the UNESCO world heritage site Merv, Turkmenistan. World Archaeol. 2009;41:489-504.

13. Armstrong BJ, Blackwood AF, Penzo-Kajewski P, Menter CG, Herries AIR. Terrestrial laser scanning and photogrammetry techniques for documenting fossil-bearing palaeokarst with an example from the Drimolen palaeocave system, South Africa. Archaeol Prospect. 2018;25:45-58.

14. Bates RC. Restoration of an artist's cast-iron loft building in SoHo in New York City. APT Bull. 1986;2013(44):39-43.

15. Beltrami C, Cavezzali D, Chiabrando F, Idelson Al, Patrucco G, Rinaudo F. 3D digital and physical reconstruction of a collapsed dome using SFM techniques from historical images. Int Arch Photogramm Remote Sens Spatial Inf Sci. 2019;XLII-2-W11:217-24. 
16. Grenier L, Antoniotti P, Hamon G, Happe D. Laas Geel (Somaliland): 5000 year-old paintings captured in 3D. Int Arch Photogramm Remote Sens Spatial Inf Sci. 2013;XL-5-W2:283-8.

17. Khunti R. The problem with printing Palmyra: exploring the ethics of using 3D printing technology to reconstruct heritage. Stud Digit Herit. 2018;2:1-12.

18. Presti SL, Paola FD, Mineo S. Artificial stone in architecture: new restoration techniques of intervention in the Utveggio castle in Palermo. Conserv Sci Cult Herit. 2012;11:195-217.

19. Yeo JM, Jo YH, Kim YT, Lee YW. Applying virtual restoration modeling and sand printing of weathered rampart stone based on three-dimensional scanning. In: 2018 3rd digital heritage international congress held jointly with 24th international conference on virtual systems \& multimedia, San Francisco; 2018.

20. Wachowiak MJ, Karas BV. 3D scanning and replication for museum and cultural heritage applications. J Am Inst Conserv. 2009;48:141-58.

21. Bruno F, Bruno S, De Sensi G, Luchi M, Mancuso S, Muzzupappa M. From $3 \mathrm{D}$ reconstruction to virtual reality: a complete methodology for digital archaeological exhibition. J Cult Herit. 2010;11:42-9.

22. Vlahakis V, loannidis M, Karigiannis J, Tsotros M, Gounaris M, Stricker D, Gleue T, Daehne P, Almeida L. Archeoguide: an augmented reality guide for archaeological sites. IEEE Comput Graph Appl. 2002;22:52-60.

23. Anderson W, Krsmanovic D. Critiquing the archaeological diary. Archeologische Ervaringen. 2008;6:29-40.

24. Núñez MA, Buill F, Edo M. 3D model of the Can Sadurní cave. J Archaeol Sci. 2013:40:4420-8.

25. Tsiafaki D, Michailidou N. Benefits and problems through the application of 3D technologies in archaeology: recording, visualisation, representation and reconstruction. Sci Cult. 2015;1:37-45.

26. Katsianis M, Tsipidis S, Kotsakis K, Kousoulakou A. A 3D digital workflow for archaeological intra-site research using GIS. J Archaeol Sci. 2008;35:655-67.

27. Mathys A, Brecko J, Van den Spiegel D, Semal P. 3D and challenging materials. Digital Heritage International Congress: Granada; 2015.

28. Mathys A, Brecko J, Semal P. Comparing 3D digitizing technologies: what are the differences. In: 2013 digital heritage international congress, Marseille; 2013

29. Canciani M, Falcolini C, Buonfiglio M, Pergola S, Saccone M, Mammì B, Romito G. A method for virtual anastylosis: the case of the arch of Titus at the Circus maximus in Rome. ISPRS Ann Photogramm Remote Sens Spatial Inf Sci. 2013;II-5/W1:61-6.

30. Stamatopoulos MI, Anagnostopoulos C. Simulation of an archaeological disaster: reassembling a fragmented amphora using the thickness profile method. Cham: Springer; 2018.

31. Laycock SD, Bell GD, Corps N, Mortimore DB, Cox G, May S, Finkel I. Using a combination of micro-computed tomography, CAD and 3D printing techniques to reconstruct incomplete 19th-century cantonese chess pieces. J Comput Cult Herit. 2015;7:1-6.

32. Papaioannou G, SchreckT, Andreadis A, Mavridis P, Gregor R, Sipiran I, Vardis K. From reassembly to object completion: a complete systems pipeline. J Comput Cult Herit. 2017;10:1-22.

33. Fatuzzo G, Mussumeci G, Oliveri SM, Sequenzia G. The, "Guerriero di Castiglione": reconstructing missing elements with integrated nondestructive 3D modelling techniques. J Archaeol Sci. 2011;38:3533-40.

34. Xu J, Ding L, Love PED. Digital reproduction of historical building ornamental components: from 3D scanning to 3D printing. Autom Constr. 2017;76:85-96

35. Arbace L, Sonnino E, Callieri M, Dellepiane M, Fabbri M, Idelson Al, Scopigno R. Innovative uses of 3D digital technologies to assist the restoration of a fragmented terracotta statue. J Cult Herit. 2013;14:332-45.

36. Bigliardi G, Dioni P, Panico G. Restauro e innovazione al Palazzo Ducale di Mantova: la stampa 3D al servizio dei Gonzaga. Archeomatica. 2015;6:40-4.

37. Hayes J, Fai S, Kretz S, Ouimet C, White P. Digitally-assisted stone carving of a relief sculpture for the parliament buildings national historic site of Canada. ISPRS Ann Photogramm Remote Sens Spatial Inf Sci. 2015;II-5/ W3:97-103.

38. Tucci G, Bonora V, Conti A, Fiorini L. High-quality 3D models and their use in a cultural heritage conservation project. Int Arch Photogramm Remote Sens Spatial Inf Sci. 2017;XLII-2-W5:687-93
39. Lee HS, Wi KC. Restoration of earthenware \& porcelain cultural assets using 3D printing. J Conserv Sci. 2015;31:131-45.

40. Lamb N, Banerjee S, Banerjee NK. Automated reconstruction of smoothly joining 3D printed restorations to fix broken objects. In: Proceedings of the ACM symposium on computational fabrication, Pittsburgh; 2019.

41. Kalasarinis I, Koutsoudis A. Assisting pottery restoration procedures with digital technologies. Int J Comput Methods Herit Sci. 2019;3:20-30.

42. Jo YH, Hong S. Application of three-dimensional scanning, haptic modeling, and printing technologies for restoring damaged artifacts. J Conserv Sci. 2019;35:71-80.

43. Park MJ, Hwang HS, Hong SY. a study on the restoration of Chimi excavated the Wangheungsa temple site using 3D scanning and computer numerical control. J Conserv Sci. 2019;35:217-25.

44. Fragkos S, Tzimtzimis E, Tzetzis D, Dodun O, Kyratsis P. 3D laser scanning and digital restoration of an archaeological find. MATEC Web Conf. 2018;178:3013-8.

45. Haesoon L, Haesoon W. Restoration of a white porcelain pitcher using 3D printing. Conserv Sci Mus. 2015;16:122-37.

46. Yang Y. 3D printing technology in the application of ceramic restoration and replication. Sci Conserv Archaeol. 2015;27:110-3.

47. Zhou P, Shui W, Qu L, Gao F, Wu Z. Case study: missing data computation and $3 \mathrm{D}$ printing application in symmetrical artifact restoration. In: The symposium ACM, Anaheim, USA; 2016.

48. Bahrampour S, Karimi AH. Using three dimensional printer for reconstruction of historic glass objects. Maremat Me'mari-e Iran. 2016;1:115-26.

49. Gaspari A, Eric M, Odar B. A Palaeolithic wooden point from Ljubljansko barje, Slovenia. Oxford: Oxbow Books; 2011.

50. Fantini M, Crescenzio FD, Persiani F, Benazzi S, Gruppioni G. 3D restitution, restoration and prototyping of a medieval damaged skull. Rapid Prototyp J. 2008;14:318-24

51. Larkin NR, Porro LB. Three legs good, four legs better: making a quagga whole again with 3D printing. Collect Forum. 2016;30:73-84.

52. Hernández-Muñoz Ó, Sánchez-Ortiz A. Digitalización e impresión 3D para la reconstrucción de pérdidas volumétricas en un modelo anatómico de cera del siglo XVIII. Conservar Património. 2019;30:59-72.

53. Idelson Al, Pannuzi S, Brunetto A, Galanti G, Giovannone C, Massa V, Serinoa C, Vischetti F. Use of 3D technologies within the conservation of the ancient windows of the basilica of S. Sabina in Rome. Construction of exhibition stands in carbon composite on a milled structure. Int Arch Photogramm Remote Sens Spatial Inf Sci. 2017; XLII-5-W1:593-8.

54. Hou M, Yang S, Hu Y, Wu Y, Jiang L, Zhao S, Wei P. Novel method for virtual restoration of cultural relics with complex geometric structure based on multiscale spatial geometry. Int J Geo-Inf. 2018;7(9):353-72.

55. Setty S, Mudenagudi U. Region of interest-based 3D inpainting of cultural heritage artifacts. ACM J Comput Cult Herit. 2018;11(9):2-21.

56. Yang $Y$, Ohtake $Y$, Suzuki H. Mesh processing for improved perceptual quality of 3D printed relief. J Comput Des Eng. 2021;8:115-24.

57. Barreau J, Nicolas T, Bruniaux G, Petit E, Petit Q, Bernard Y, Gaugne R, Gouranton V. Ceramics fragments digitization by photogrammetry, reconstructions and applications. In: International conference on cultural heritage, Cyprus; 2014

58. Niquet N, Sánchez-López N, Mas-Barberà X. Development of reversible intelligent prosthesis for the conservation of sculptures. A case study. J Cult Herit. 2020;43:227-34.

59. Zhang P. Application of detachable fragments made by $3 D$ printing in the restoration of bronze wares. Sci Conserv Archaeol. 2021;33:1-9.

60. Kong P. Late Northern Song Dynasty-Black Ding vase with gold foil decoration. https://www.christies.com.cn/zh/lot/lot-6146018. Accessed 15 Sept 2021

61. Gardellin R. Gold and silver decoration on Song Dynasty Wares_-Part 1. Oriental Art. 2019;51:11-29.

62. Bunkakan Y. Chinese ceramics from the museum Bunkakan collection (大 和文华馆所藏中国陶瓷). Nara: Convenience Hall Co.; 1974.

63. Black Ding bowl with a design of floral sprays in gold. https://www. moaart.or.jp/en/collections/117/. Accessed 15 Sept 2021.

64. Kim YM. Chinese porcelain excavated from the Goryeo site in the National Central Museum of Korea. Cult Relics. 2010;4:77-95.

65. Aura-Castro E, Díaz-Marín C, Mas-Barberà X, Sánchez M, VendrellVidal E. Characterization of 3D printing filaments applied in restoration of sensitive archaeological objects using rapid prototyping. Rapid Prototyp J. 2021:27(4):645-57. 
66. Tsukada M, Rizzo A, Granzotto C. A new strategy for assessing off-gassing from museum materials: air sampling in Oddy test vessels. J Am Inst Conserv. 2012;37(1):1-7.

67. Cimino D, Rollo G, Zanetti M, Bracco P. 3D printing technologies: are their materials safe for conservation treatments? IOP conference series. Mater Sci Eng. 2018;364:12029.

68. Yao B, Zhou Z, Duan L, Chen Z. Characterization of three-point bending properties of metal-resin interpenetrating phase composites. RSC Adv. 2018:8:16171-7.

69. Xue X, Liao J, Vincze G, Pereira AB, Barlat F. Experimental assessment of nonlinear elastic behaviour of dual-phase steels and application to springback prediction. Int J Mech Sci. 2016;117:1-15.

70. Robertson AR, The CIE. Color-difference formulae. Color Res Appl. 1976;1977(2):7-11.

\section{Publisher's Note}

Springer Nature remains neutral with regard to jurisdictional claims in published maps and institutional affiliations.

\section{Submit your manuscript to a SpringerOpen ${ }^{\odot}$ journal and benefit from:}

- Convenient online submission

- Rigorous peer review

- Open access: articles freely available online

- High visibility within the field

- Retaining the copyright to your article

Submit your next manuscript at $\boldsymbol{\nabla}$ springeropen.com 